\title{
CAMA
}

Centre for Applied Macroeconomic Analysis

\section{Prudential Capital Controls or Bailouts? The Impact of Different Collateral Constraint Assumptions}

\section{CAMA Working Paper 25/2014 March 2014}

Mitsuru Katagiri

Bank of Japan

Ryo Kato

Bank of Japan

Takayuki Tsuruga

Graduate School of Economics, Kyoto University and

Centre for Applied Macroeconomic Analysis, ANU

\section{Abstract}

A fast growing literature on small open economy models with pecuniary externalities has provided the theoretical grounds for the policy analysis of macro prudential regulations. Using the framework of Jeanne and Korinek (2010), we investigate whether a subsidy on debt during crises as a form of bailout can outperform prudential capital controls. We show that the result depends on the functional form of the collateral constraint faced by households. If households collateralize their assets that they purchase at the same time as their borrowing, subsidizing debt during crises is preferable. If, on the other hand, the maximum borrowing is constrained by the value of their assets that they have purchased before they borrow, a stronger case can be made for prudential capital controls. 


\section{Keywords}

Financial crises, Credit externalities, Bailouts, Macroprudential policies

JEL Classification

E32, G01, G18

Address for correspondence:

(E) cama.admin@anu.edu.au

The Centre for Applied Macroeconomic Analysis in the Crawford School of Public Policy has been established to build strong links between professional macroeconomists. It provides a forum for quality macroeconomic research and discussion of policy issues between academia, government and the private sector.

The Crawford School of Public Policy is the Australian National University's public policy school, serving and influencing Australia, Asia and the Pacific through advanced policy research, graduate and executive education, and policy impact. 


\title{
Prudential Capital Controls or Bailouts? The Impact of Different Collateral Constraint Assumptions*
}

\author{
Mitsuru Katagiri ${ }^{\prime}$ Ryo Kato $\ddagger$ and Takayuki Tsuruga ${ }^{\S}$
}

February 2014

\begin{abstract}
A fast growing literature on small open economy models with pecuniary externalities has provided the theoretical grounds for the policy analysis of macro prudential regulations. Using the framework of Jeanne and Korinek (2010), we investigate whether a subsidy on debt during crises as a form of bailout can outperform prudential capital controls. We show that the result depends on the functional form of the collateral constraint faced by households. If households collateralize their assets that they purchase at the same time as their borrowing, subsidizing debt during crises is preferable. If, on the other hand, the maximum borrowing is constrained by the value of their assets that they have purchased before they borrow, a stronger case can be made for prudential capital controls.
\end{abstract}

JEL Classification: E32, G01, G18

Keywords: Financial crises, Credit externalities, Bailouts, Macroprudential policies

*We would like to Gianluca Benigno, Timothy Kam, Takashi Kamihigashi, Shigeto Kitano, Keiichiro Kobayashi, Teruyoshi Kobayashi, Césaire Meh, Eric R. Young and the staff of Bank of Japan for helpful comments. We also thank seminar and conference participants at Hitotsubashi University, Kobe University, National Graduate Institute for Policy Studies, Victoria University of Wellington, the 14th Annual Macro Conference, the 10th Biennial Pacific Rim Conference, the 18th Australasian Macroeconomic Workshop, the Society for Economic Dynamics Meeting, the 19th International Conference of Computing in Economics and Finance, the Asian Meeting of the Econometric Society, and the 2013 Annual Meeting of Japan Society of Monetary Economics for helpful discussions. Takayuki Tsuruga gratefully acknowledges the financial support of a Grant-in-Aid for Scientific Research. Views expressed in this paper are those of the authors and do not necessarily reflect the official views of the Bank of Japan.

${ }^{\dagger}$ Bank of Japan; e-mail: mitsuru.katagiri@boj.or.jp

$\ddagger$ Bank of Japan; e-mail: ryou.katou@boj.or.jp

$\S$ Graduate School of Economics, Kyoto University and the Centre for Applied Macroeconomic Analysis; e-mail: tsuruga@econ.kyoto-u.ac.jp 


\section{Introduction}

Should policymakers in emerging market economies rely on macro prudential policies during normal times or bail out borrowers at the time of a financial crisis? Recent studies have highlighted the importance of prudential controls on cross-border capital flows and macro prudential regulations to prevent inefficient boom-bust cycles. Among others, Jeanne and Korinek (2010, hereafter JK), Bianchi (2011), and Bianchi and Mendoza (2012) emphasize that market-determined asset prices can generate pecuniary externalities that distort financing decisions of economic agents. A key ingredient in their models is an occasionally binding collateral constraint that depends on the market value of the collateral. Based on the framework with this constraint, these early studies advocate that the government should preemptively impose a Pigouvian tax on debt during normal times and internalize the externalities. ${ }^{1}$

This paper extends the JK model to consider policy prescriptions for coping with crises. In particular, we consider two assumptions on the collateral constraint and investigate how the difference in the assumptions affects policy prescriptions for coping with crises. The two collateral constraints differ in the timing in which households' assets are collateralized. To emphasize the timing, we call the collateral constraints either a "beginning-of-period" or an "end-of-period" collateral constraint. The "beginning-of-period" collateral constraint is assumed in JK. Under this constraint, the households collateralize the assets that they have purchased before they borrow. On the other hand, under the "end-of-period" collateral constraints, households collateralize the assets that they purchase at the same time as borrowing. This end-of-period collateral constraint has also been employed by other studies (e.g., Kiyotaki and Moore, 1997 and Bianchi and Mendoza, 2012).

We find that the choice between the two assumptions is not innocuous. We show that, under the beginning-of-period collateral constraint, subsidizing debt during crises cannot achieve better allocation than that under the laissez-faire economy. In other words, the bailout is neutral. By contrast, subsidizing debt during crises can achieve the first-best allocation if households are subject to an "end-of-period" collateral constraint.

Our results suggest that policymakers should have knowledge of the structure of the collateral constraint that the households are faced with. As JK and others suggested, prudential

\footnotetext{
${ }^{1}$ More recent papers include Benigno, Chen, Otrok, Rebucci, and Young (2012a, 2012b, 2013), Bianchi (2013), Bianchi and Mendoza (2013), Dávilla (2011), Jeanne and Korinek (2012), Koinek and Simsek (2013). Farhi and Werning $(2012,2013)$ and Schmitt-Grohé and Uribe $(2012,2013)$ argue for the prudential capital controls under the nominal price or wage rigidities.
} 
capital controls can achieve the second-best allocation. If the beginning-of-period collateral constraint is a more plausible assumption, a policy prescription is that policymakers should rely on the prudential capital controls via the Pigouvian tax on debt. This is because a bailout through subsidizing debt is neutral in terms of welfare. Conversely, under the endof-period collateral constraint, the bailout can achieve the first-best allocation and thus is more desirable than the prudential capital controls.

In the literature, early studies have noted that the government can restore the first-best allocation in some models with an occasionally binding collateral constraint. For example, using a model similar to Bianchi (2011), Benigno, Chen, Otrok, Rebucci, and Young (2012a, hereafter BCORY) show that, if the government can use additional distortionary policy instruments on top of capital controls (e.g., a price support policy in the form of a subsidy on collateral or collateralized nontradable goods), then the collateral constraint can always be removed and the government can achieve the first-best allocation. ${ }^{2}$ Our finding starkly contrasts with BCORY. In this paper, "bailout" refers to the subsidy on foreign debt. To keep the comparison between prudential capital controls and bailouts fair, we assume that the government is given a single policy instrument that affects the cost of borrowing from abroad (i.e., intervention in the credit market). In our model, the government can achieve the first-best allocation without relying on additional distortionary policy measures such as outright purchase of the collateral and subsidy on nontradable good consumption.

If bailouts are theoretically desirable, the next question for policymakers would be whether the bailouts are practically feasible. To answer this question, the present paper also performs numerical experiments and assesses the size and frequency of policy interventions in credit markets. Our assessment suggests that strong expectations for bailouts akin to moral hazard lead to an unrealistically large bailout size and a high frequency of intervention. In fact, on average, a large lump-sum tax equivalent to as much as 31.6 percent of annual household income must be imposed to achieve the first-best allocation. On the frequency, the government needs to intervene almost every year. These results point to a large gap compared with the actual observation because very few - perhaps no - governments in emerging market economies have embarked on such large bailouts with such high frequency. Our experiments

\footnotetext{
${ }^{2}$ See also Jeanne and Korinek (2012) and Benigno, Chen, Otrok, Rebucci, and Young (2012b) for the case where multiple policy instruments are available for crisis management. Schmitt-Grohé and Uribe (2013) show that the open economy model with downward nominal wage rigidities can give rise to pecuniary externalities. They argue that bailouts by devaluation of the country's currency could restore the first-best allocation. Likewise, using a model of banking, Green (2010) argues that bailouts can lead to a socially efficient outcome.
} 
suggest that further research be called for to explore what can fill the gap.

This paper is organized as follows. Section 2 introduces the JK model with the two collateral constraints used for our comparisons. Section 3 extends the JK model to consider the optimal debt subsidy as a bailout. Section 4 performs numerical experiments. Section 5 concludes.

\section{Two collateral constraints}

We begin with a small open economy model developed by JK. Suppose that the utility of identical atomistic households is given by $u\left(c_{0}\right)+u\left(c_{1}\right)+c_{2}$, where $u(\cdot)$ is assumed to take a CRRA form and $c_{t}$ represents consumption in period $t$. Domestic households' budget constraints for each period are given by

$$
\begin{aligned}
c_{0}+p_{0} \theta_{1} & =d_{1}+p_{0} \\
c_{1}+d_{1}+p_{1} \theta_{2} & =e+d_{2}+p_{1} \theta_{1} \\
c_{2}+d_{2} & =\theta_{2} y
\end{aligned}
$$

where $d_{t}$ is the debt to be repaid at the beginning of the period $t$ and $\theta_{t}$ represents the domestic collateral held by the households at the beginning of period $t$. Here, $p_{t}$ is the price of collateral traded in a competitive market. Throughout all periods, the world interest rate is set to zero for simplicity. At the beginning of period 0, the households hold one unit of collateral. In this period, they borrow $d_{1}$ from abroad and purchase $\theta_{1}$ as well as the consumption goods. ${ }^{3}$ In period 1 , the households have three sources of inflow: sales of collateral $p_{1} \theta_{1}$, new borrowing $d_{2}$, and an endowment $e$ that is not pledgeable to foreign lenders. They use them for consumption $c_{1}$, repaying $d_{1}$, and purchasing collateral $\theta_{2}$. In the final period, the households must repay $d_{2}$ after receiving returns on collateral $y$. Following JK, we assume that the return on collateral can be acquired only by domestic agents and the value of collateral in period 2 is lost after the households receive $y$. We also assume that the supply of collateral assets is inelastic and normalized to one. In this JK model, the linear utility in period 2 implies that, if there is no collateral constraint, consumption in periods 0 and 1 is unity (i.e., the first-best level of consumption).

The model introduces a collateral constraint for $d_{2}$. As JK discuss, a low value of $e$ may result in the binding collateral constraint and precipitate a crisis (e.g., sudden stop in

\footnotetext{
${ }^{3}$ Without loss of generality, the initial value of foreign debt is set to zero.
} 
capital inflows). With the binding collateral constraint in period 1 , the desired borrowing is generally impossible and the households must accept a large reduction in $c_{1}$. As such, period 1 corresponds to the period of a crisis.

\subsection{The beginning-of-period collateral constraint}

Each household faces a collateral constraint of the form

$$
d_{2} \leq \phi \theta_{1} p_{1}
$$

Note that, following JK, the borrowing capacity is constrained by the market value of collateral at the beginning of period 1 . The parameter $\phi \in(0,1]$ represents the ceiling on the leverage in the collateral constraint. ${ }^{4}$ In a symmetric equilibrium, $\theta_{1}$ must be unity because the supply of collateral asset is one. Not surprisingly, pecuniary externalities arise from the feedback loop between the collateral price and borrowing. When a sufficiently low $e$ takes place, the collateral constraint binds. The households try to prevent consumption reduction by decreasing net demand for their collateral. The households' deleveraging results in declines in collateral prices, and the decline in $p_{1}$ further tightens their collateral constraints. While each atomistic household takes $p_{1}$ as given, the households' decision as a whole has the general equilibrium effect on $p_{1}$. As a result, the general equilibrium effect cannot be internalized by price-taking households and the laissez-faire equilibrium is not generally Pareto efficient. This result calls for the "macro prudential policies" that have been widely discussed in the literature. ${ }^{5}$

JK show that, in their stochastic model where $e$ is random, a Pigouvian $\operatorname{tax} \tau$ can replicate the second-best allocation solved by the constrained social planner. ${ }^{6}$ Replace the period- 1 budget constraint (2) by

$$
c_{1}+(1+\tau) d_{1}-T+p_{1} \theta_{2}=e+d_{2}+p_{1} \theta_{1},
$$

where the government runs a balanced budget: the lump-sum transfers $T$ equal tax on debt

\footnotetext{
${ }^{4}$ We consider a slightly more general constraint because JK assume $\phi=1$.

${ }^{5}$ Examples of this research include Bianchi (2011), Jeanne and Korinek (2011), Korinek (2011), Bianchi and Mendoza (2012) and Benigno et al. (2012a, 2012b, 2013).

${ }^{6}$ See JK for details on the constrained social planner's problem in maximizing the households' utility subject to the resource constraints and the same collateral constraint as that of households.
} 
$\tau d_{1}$. In $\mathrm{JK}$, the following macro prudential tax is proposed:

$$
\tau=\frac{\phi \mathbb{E}_{0}\left[\lambda_{s p} p^{\prime}\left(m_{1}\right)\right]}{\mathbb{E}_{0}\left[u^{\prime}\left(c_{1}\right)\right]}
$$

where $\mathbb{E}_{0}$ denotes the expectations operator conditional on the information at $t=0 .^{7}$ In (6), $\lambda_{s p}$ is the Lagrange multiplier for the collateral constraint that the social planner faces, $u^{\prime}\left(c_{1}\right)$ denotes the marginal utility of consumption, and $p^{\prime}\left(m_{1}\right)>0$ is the derivative of $p_{1}$ with respect to the level of the liquid net worth $m_{1} \equiv e-d_{1}$. The shadow price of holding debt $\lambda_{s p}$ and the asset pricing function $p\left(m_{1}\right)$ are obtained from the constrained social planner's problem in which she internalizes the general equilibrium effect of $m_{1}$ on $p_{1} .{ }^{8}$ This prudential tax on debt reduces borrowing in the pre-crisis period and can mitigate reductions in asset prices in the crisis period.

\subsection{The end-of-period collateral constraint}

As a variant of the collateral constraint (4), consider

$$
d_{2} \leq \phi \theta_{2} p_{1}
$$

where the value of collateral is evaluated by the end-of-period holding of collateral $\theta_{2}$, rather than $\theta_{1}$. As discussed in JK, their key results on prudential taxes remain the same across the two collateral constraints: ${ }^{9}$ (i) the same collateral constraint in equilibrium (i.e., $d_{2} \leq \phi p_{1}$ ); (ii) the same feedback loop between the collateral price and borrowing; and (iii) the same form of the Pigouvian tax. These results remain essentially unaltered even under the infinitehorizon setting. ${ }^{10}$

\footnotetext{
${ }^{7}$ More specifically, the information set does not include the realization of $e$.

${ }^{8}$ The asset pricing function is given by $p\left(m_{1}\right)=y / u^{\prime}\left(c_{1}\right)=y / u^{\prime}\left(d_{2}+m_{1}\right)$ and differs from the asset pricing function under the laissez-faire economy. In other words, JK follow the "constrained efficiency" definition of Kehoe and Levine (1993) in their social planner's problem.

${ }^{9}$ See footnote 4 in JK.

${ }^{10}$ Jeanne and Korinek (2011) numerically reconfirm the robustness to the assumptions on collateral constraints in Appendix A.2.
} 


\section{The optimal debt subsidy as a bailout}

We consider how changes in the assumption regarding the collateral constraint affect bailouts. For simplicity, we assume in this section that $e$ is deterministic rather than stochastic. This simplification allows us to obtain an explicit solution for the optimal debt subsidy, but has no effect on our argument.

To introduce bailouts, we replace (2) by

$$
c_{1}+d_{1}+p_{1} \theta_{2}=e+(1+s) d_{2}-S+p_{1} \theta_{1},
$$

where $s \geq 0$ is a subsidy on debt and $S$ is the lump-sum tax, satisfying $S=s d_{2} \cdot{ }^{11}$ A balanced government budget ensures that household resources are kept unchanged both intra- and inter-temporally. Thus, the only distinction between the prudential capital controls and bailouts is the question of whether to raise the cost of debt before a crisis or to reduce it during one.

In the following two subsections, we will present propositions on the optimal subsidy under the two differing collateral constraints, (4) and (7). Then, we will interpret the two propositions in the context of policy implications.

\subsection{The beginning-of-period collateral constraint}

The households maximize their utility $u\left(c_{0}\right)+u\left(c_{1}\right)+c_{2}$, subject to the budget constraints (1), (8), (3) and the beginning-of-period collateral constraint (4). The first-order conditions are

$$
\begin{aligned}
u^{\prime}\left(c_{0}\right) & =u^{\prime}\left(c_{1}\right) \\
(1+s) u^{\prime}\left(c_{1}\right) & =1+\lambda_{m} \\
p_{0} & =p_{1}\left[\frac{u^{\prime}\left(c_{1}\right)+\lambda_{m} \phi}{u^{\prime}\left(c_{0}\right)}\right] \\
p_{1} & =\frac{y}{u^{\prime}\left(c_{1}\right)} .
\end{aligned}
$$

Here $\lambda_{m}$ represents the Lagrange multiplier for (4). In (10), the households choose $d_{2}$ by comparing the marginal cost $1+\lambda_{m}$ on the right-hand side with the marginal benefit $(1+s) u^{\prime}\left(c_{1}\right)$

\footnotetext{
${ }^{11}$ Following Jeanne and Korinek (2012), our policy analysis rules out the possibility that the government uses the non-distortionary inter-temporal lump-sum taxes and transfers to fully relax the collateral constraint.
} 
on the left-hand side. Other things being equal, a higher subsidy on debt encourages a household to hold more debt during a crisis. The asset pricing equations in each period are given by (11) and (12). In (11), $\lambda_{m} \phi p_{1}$ represents the extra benefit of holding more collateral under the beginning-of-period collateral constraint. This extra benefit increases only $p_{0}$ but has no effect on $p_{1}$.

The first proposition establishes that, under the beginning-of-period collateral constraint, subsidizing debt during a crisis does not improve the welfare, compared to the laissez-faire economy.

Proposition 1 Suppose that the household maximizes the utility of $u\left(c_{0}\right)+u\left(c_{1}\right)+c_{2}$ subject to (1), (8), (3) and the beginning-of-period collateral constraint (4). Then, the optimal subsidy on debt $s^{*}$ is zero if $(2-e) / y \leq \phi \leq 1$. If $0<\phi<(2-e) / y$, on the other hand, the allocation is fully independent of $s$ and is equivalent to the allocation under the laissez-faire economy.

Proof. It is straightforward to obtain the unconstrained first-best allocation: $c_{F B, 0}=$ $c_{F B, 1}=d_{F B, 1}=1, c_{F B, 2}=y-2+e$, and $d_{F B, 2}=2-e$. Likewise, it can be easily shown that the price of collateral under the first-best allocation is $p_{F B, 0}=p_{F B, 1}=y$. For $(2-e) / y \leq \phi \leq 1$, the collateral constraint does not bind under the laissez-faire economy $\left(d_{F B, 2}<\phi p_{F B, 1}\right)$. Hence, the optimal subsidy $s^{*}$ is trivially zero. We next consider the case of $0<\phi<(2-e) / y$, which means that the collateral constraint binds under the laissezfaire economy. In this case, together with (12), (4) implies (i) $d_{2}=\phi y / u^{\prime}\left(c_{1}\right)$. Because of the market clearing conditions for collateral (i.e., $\theta_{1}=\theta_{2}=1$ ) and the government budget constraint, (1), (8), and (3) can be simplified to (ii) $c_{0}=d_{1}$, (iii) $c_{1}+d_{1}=e+d_{2}$, and (iv) $c_{2}+d_{2}=y$. Furthermore, (9) implies that $(\mathrm{v}) c_{0}=c_{1}$. The allocation in this decentralized economy, $\left\{c_{0}, c_{1}, c_{2}, d_{1}, d_{2}\right\}$, can be fully determined by (i) - (v) if the unique equilibrium exists. Because (i) - (v) do not include $s$, the resulting allocation is fully independent of $s$. Therefore, the allocation must be equivalent to that under the laissez-faire economy.

\subsection{The end-of-period collateral constraint}

We next consider the same bailout under the end-of-period collateral constraint (7). While the first-order conditions (9) and (10) remain the same as before, (11) and (12) must be 
replaced by

$$
\begin{aligned}
& p_{0}=p_{1} \\
& p_{1}=\frac{y}{u^{\prime}\left(c_{1}\right)-\lambda_{m} \phi},
\end{aligned}
$$

respectively. In contrast to (11) and (12), the extra benefit of holding the collateral $\left(\lambda_{m} \phi p_{1}\right)$ affects both $p_{0}$ and $p_{1}$ under the end-of-period collateral constraint.

The next proposition states that the optimal $s$ can replicate the unconstrained first-best allocation. Proposition 2 summarizes our second main result.

Proposition 2 Suppose that the household maximizes the utility of $u\left(c_{0}\right)+u\left(c_{1}\right)+c_{2}$ subject to (1), (8), (3), and the end-of-period collateral constraint (7). Then, there exists timeconsistent $s^{*}$ with which the decentralized equilibrium achieves the unconstrained first-best allocation, where $s^{*}$ is equal to the equilibrium shadow price of holding debt in the decentralized economy:

$$
s^{*}=\lambda_{m}\left(s^{*}\right) \geq 0
$$

If $0<\phi<(2-e) / y, s^{*}$ is given by

$$
s^{*}=\frac{1}{\phi}-\frac{y}{2-e}>0 .
$$

Otherwise, $s^{*}=0$.

Proof. As in the proof of Proposition 1, the optimal subsidy for $(2-e) / y \leq \phi \leq 1$ is trivial: $s^{*}=\lambda=0$ and the collateral constraint does not bind under $s^{*}$. For $0<\phi<$ $(2-e) / y, d_{F B, 2}>\phi p_{F B, 1}$. If a positive $s^{*}$ exists, it must be the case that $\lambda_{m}\left(s^{*}\right)>0$ and $d_{F B, 2}=\phi p_{1}$. Here, from (10), we note that $\lambda_{m}$ depends on $s$. Substituting the unconstrained first-best allocation into (10) and (14) yields $s=\lambda_{m}(s)$ and $p_{1}=y /(1-s \phi)$, respectively. Therefore, $s^{*}$ in (16) is obtained by eliminating $p_{1}$ from $p_{1}=y /(1-s \phi)$ and $d_{F B, 2}=$ $\phi p_{1}$. Because $d_{F B, 2}$ is feasible under $p_{1}$ satisfying $p_{1}=y /\left(1-s^{*} \phi\right), s^{*}$ achieves the firstbest allocation $\left\{c_{F B, 0}, c_{F B, 1}, c_{F B, 2}, d_{F B, 1}, d_{F B, 2}\right\}$. The solution $s^{*}$ is a function of exogenous variables and hence time-consistent.

\subsection{Interpretation}

Proposition 1 indicates that, if the collateral constraint is given by (4) as in JK, subsidizing debt during crises does not improve the welfare. This result implies that the prudential cap- 
ital controls that can achieve the second-best allocation are strictly preferred to the bailout. By contrast, however, Proposition 2 shows that, if the collateral constraint is replaced by (7), the optimal subsidy $s^{*}$ can prevent fire sales of collateral and achieve the first-best allocation. In terms of policy prescription, the bailout outperforms the prudential capital controls under the assumption of the end-of-period collateral constraint.

The key to understanding our result is the price of collateral $p_{1}$ at a time of crisis. Suppose that the collateral constraint binds in period 1 (i.e., $0<\phi<(2-e) / y$ ). In this case, the government may wish to intervene in the credit market with $s>0$ if it can inflate the price of collateral. Moreover, the households can enjoy even the first-best level of consumption if the asset price is inflated to ensure that $d_{F B, 2}=\phi p_{1}$. Therefore, $d_{F B, 2}$ uniquely determines the target level of the asset price for the government:

$$
p_{1}=\frac{d_{F B, 2}}{\phi}=\frac{2-e}{\phi}>y,
$$

where the strict inequality is ensured by the assumption of $\phi<(2-e) / y$.

The question is whether the government can inflate asset prices. Under (4), the subsidy on new borrowing has no effect on households' decisions because their borrowing capacity is predetermined by $\phi \theta_{1} p_{1}$. Households' demand for collateral $\left(\theta_{2}\right)$ is not stimulated by the subsidy. As a result, $p_{1}$ remains unaffected by the subsidy and the only option for the households is to demand less collateral $\left(\theta_{2}\right)$ to compensate for consumption. After all, the allocation turns out to be the same as that under the laissez-faire economy with a low price of collateral. By contrast, under (7), households know that if they buy more collateral $\left(\theta_{2}\right)$, then they can borrow more, because $\theta_{2}$ affects their borrowing capacity. The lower cost of new debt owing to the subsidy provides them with financing for the purchase of new collateral $\left(\theta_{2}\right)$. This financing for the new collateral purchase stimulates the demand, which results in higher $p_{1}$.

From the viewpoint of the government, $p_{1}$ under (14) can be seen as a function of the policy instrument $s$. In particular, along with (10), the asset pricing equation (14) can be expressed as

$$
p_{1}=\frac{y}{[1-(1+s) \phi] u^{\prime}\left(c_{1}\right)+\phi} .
$$

This equation indicates that the government can control the price of collateral by choosing 
$s$. If the government sets $s=s^{*}=\lambda_{m}\left(s^{*}\right)$,

$$
p_{1}=\frac{y}{1-s^{*} \phi} \text {. }
$$

This $s^{*}$ is consistent with the target price given by (17), while satisfying all the first-order conditions and the constraints. Hence, under the end-of-period collateral constraint, the government can achieve the first-best allocations.

In the literature, BCORY propose a different policy prescription that can restore the first-best allocation. In this regard, Proposition 2 in our paper is related to their findings. The optimal subsidy in our model, however, starkly differs from the BCORY's prescription in three respects. First, the policy instrument in this paper differs from BCORY's. The government in BCORY subsidizes the household collateral purchase, while that in our model subsidizes household borrowing. Intervening in collateral markets may require additional capacity (i.e., additional policy instruments) of the government. ${ }^{12}$ Our argument is applicable to any government that has the capacity to implement capital controls (i.e., the capacity to affect the cost of borrowing). The second difference is slightly technical. Under the BCORY's prescription, the collateral constraint never binds. In the context of our model, this means that $d_{F B, 2}<\phi p_{1}$ and $\lambda_{m}=0$. To ensure the effectiveness of the optimal subsidy in our model, $\lambda_{m}$ needs to take strictly positive values, because, as indicated by (14), the non-zero Lagrange multiplier enables asset price inflation. Third, the BCORY's prescription can also be interpreted as crisis prevention rather than bailouts, because crises never take place in BCORY. By contrast, the optimal subsidy in our model requires actual fiscal expenditure and, in fact, needs to be activated as a tangible intervention.

\section{Quantitative evaluation of the optimal subsidy}

Proposition 2 in the previous section indicates that theoretically there exists an "optimal bailout" in the form of subsidy on debt during a crisis. However, a natural question for policymakers would be whether the optimal subsidy is practically feasible. To answer this question, we extend the three-period model to a stochastic infinite-horizon model that can be calibrated to the data. Using the extended model, we examine (i) whether the policy

\footnotetext{
${ }^{12}$ See Propositions 3 and 4 in BCORY. They employ the collateral constraint in which the income from tradable and non tradable endowments can be pledged as collateral as in Bianchi (2011). Using this setup of the model, the government commits to supporting the relative price of non tradables to tradables during crises by either a subsidy on nontradable good consumption or a tax on tradable good consumption.
} 
intervention for implementing the "optimal bailout" is realistic in terms of the size; and (ii) how frequently the policy intervention needs to be made to restore the first-best allocation. As a preparatory step, we first show that the result of Proposition 2 continues to hold even in the case of a stochastic infinite-horizon model and that the optimal subsidy on debt becomes state-contingent. We then explore how $s^{*}$ fluctuates over time to assess the size and frequency of bailouts in a calibrated model.

\subsection{The infinite-horizon model}

We consider the stochastic infinite-horizon model, similar to Jeanne and Korinek (2011) and Bianchi and Mendoza (2012). The households choose $d_{t+1}$ and $\theta_{t+1}$ to maximize

$$
\mathbb{E}_{0}\left[\sum_{t=0}^{\infty} \beta^{t} u\left(c_{t}\right)\right]
$$

where $\beta$ is the discount factor satisfying $\beta \in(0,1)$. Each household faces the period-byperiod budget constraint:

$$
c_{t}+d_{t}+p_{t} \theta_{t+1}=\theta_{t} e_{t}+\left(1+s_{t}\right) \frac{d_{t+1}}{R}-S_{t}+p_{t} \bar{\theta}
$$

and the end-of-period occasionally binding collateral constraint:

$$
\frac{d_{t+1}}{R} \leq \phi p_{t} \theta_{t+1}
$$

In this maximization problem, $d_{t+1}$ is non-state-contingent one-period debt. The real interest rate on the non-state-contingent debt is $R>1$ rather than unity. Every period, each household receives the exogenous endowment of collateral $\bar{\theta}$, which is normalized to one. He receives a stochastic income $e_{t}$ based on the predetermined share of collateral assets $\theta_{t}$ (i.e., dividends). As before, the value of collateral is lost after receiving the return on collateral. The budget constraint here is basically the same as (8), but is also similar to (3) in terms of the returns on collateral. Finally, the collateral constraint is the same as (7) except for $R$. 
The first-order conditions are standard:

$$
\begin{aligned}
\left(1+s_{t}\right) u^{\prime}\left(c_{t}\right) & =\beta R \mathbb{E}_{t} u^{\prime}\left(c_{t+1}\right)+\lambda_{m, t} \\
p_{t} & =\beta \frac{\mathbb{E}_{t}\left[u^{\prime}\left(c_{t+1}\right) e_{t+1}\right]}{u^{\prime}\left(c_{t}\right)-\lambda_{m, t} \phi} \\
0 & =\left[\phi p_{t} \theta_{t+1}-\frac{d_{t+1}}{R}\right] \lambda_{m, t}, \lambda_{m, t} \geq 0, \text { and } \phi p_{t} \theta_{t+1}-\frac{d_{t+1}}{R} \geq 0 .
\end{aligned}
$$

In equilibrium, the markets for collateral and consumption goods clear: $\theta_{t+1}=\bar{\theta}$ and $c_{t}+d_{t}=$ $e_{t}+d_{t+1} / R$ for all $t$, respectively. As before, we assume a balanced budget of the government: $S_{t}=s_{t} d_{t+1} / R$.

The first-best allocation must satisfy the following first-order conditions:

$$
\begin{aligned}
u^{\prime}\left(c_{F B, t}\right) & =\beta R \mathbb{E}_{t}\left[u^{\prime}\left(c_{F B, t+1}\right)\right] \\
p_{F B, t} & =\beta \frac{\mathbb{E}_{t}\left[u^{\prime}\left(c_{F B, t+1}\right) e_{t+1}\right]}{u^{\prime}\left(c_{F B, t}\right)}
\end{aligned}
$$

which yield the policy functions $c_{F B, t}=c_{F B}\left(d_{t}, e_{t}\right)$ and $d_{F B, t+1}=d_{F B}\left(d_{t}, e_{t}\right)$ as functions of state variables. Likewise, the asset pricing function is obtained from the model without the collateral constraint: $p_{F B, t}=p_{F B}\left(d_{t}, e_{t}\right)$. The following proposition shows that there exists a state-contingent optimal subsidy $s_{t}=s\left(d_{t}, e_{t}\right)$ consistent with the first-best allocation in the stochastic infinite-horizon model.

Proposition 3 Suppose that the household maximizes (19) subject to (20) and the end-ofperiod collateral constraint (21). Then, there exists a price function $p_{s}\left(d_{t}, e_{t}\right)$ and a timeconsistent subsidy $s^{*}\left(d_{t}, e_{t}\right)$, with which the decentralized equilibrium characterized by (20)(24) achieves the unconstrained first-best allocation $\left\{c_{F B, t}, d_{F B, t+1}\right\}_{t=0}^{\infty}$. Furthermore, the subsidy $s_{t}^{*}=s^{*}\left(d_{t}, e_{t}\right)$ is proportional to the Lagrange multiplier for (21):

$$
s^{*}\left(d_{t}, e_{t}\right)=\frac{\lambda_{m}\left(d_{t}, e_{t} ; s_{t}^{*}\right)}{u^{\prime}\left[c_{F B}\left(d_{t}, e_{t}\right)\right]} \geq 0
$$

where $\lambda_{m}\left(d_{t}, e_{t} ; s_{t}\right)$ represents the Lagrange multiplier for the collateral constraint, given $s_{t}$. This subsidy $s_{t}^{*}$ is time-consistent. Furthermore, if $d_{F B}\left(d_{t}, e_{t}\right) / R>\phi p_{F B}\left(d_{t}, e_{t}\right), s^{*}\left(d_{t}, e_{t}\right)$ is given by

$$
s^{*}\left(d_{t}, e_{t}\right)=\frac{1}{\phi}-\frac{p_{F B}\left(d_{t}, e_{t}\right)}{d_{F B}\left(d_{t}, e_{t}\right) / R}>0 .
$$

Otherwise, $s^{*}\left(d_{t}, e_{t}\right)=0$. 
Proof. We consider two cases for the states of the economy $\left(d_{t}, e_{t}\right):(\mathrm{i}) d_{F B}\left(d_{t}, e_{t}\right) / R \leq$ $\phi p_{F B}\left(d_{t}, e_{t}\right)$ and (ii) $d_{F B}\left(d_{t}, e_{t}\right) / R>\phi p_{F B}\left(d_{t}, e_{t}\right)$. Here, the conditions distinguish whether or not the first-best level of debt is feasible in the laissez-faire economy. For each case, we will confirm that the first-order conditions $(22)-(24)$ are satisfied under $s^{*}\left(d_{t}, e_{t}\right)$ when they are evaluated at the first-best allocation $c_{F B}\left(d_{t}, e_{t}\right)$ and $d_{F B}\left(d_{t}, e_{t}\right)$.

Consider the states satisfying (i). If $s^{*}\left(d_{t}, e_{t}\right)=0, \lambda_{m}\left[d_{t}, e_{t}, s^{*}\left(d_{t}, e_{t}\right)\right]=0$. Then, the first-order conditions of (22) and (23) are the same as (25) and (26), and the allocation is the first-best. Therefore, $p_{s}\left(d_{t}, e_{t}\right)=p_{F B}\left(d_{t}, e_{t}\right)$ characterized by (26). The optimality of $s^{*}\left(d_{t}, e_{t}\right)=0$ is confirmed for the states satisfying (i).

Next, for the states satisfying (ii), consider the price of collateral that achieves $d_{F B}\left(d_{t}, e_{t}\right)$ with the binding collateral constraint. If

$$
p_{s}\left(d_{t}, e_{t}\right)=\frac{d_{F B}\left(d_{t}, e_{t}\right)}{\phi R}
$$

then (24) is satisfied together with $\lambda_{m}\left(d_{t}, e_{t} ; s^{*}\left(d_{t}, e_{t}\right)\right) \geq 0$. Combining (27), (23), and (29) yields

$$
\frac{d_{F B}\left(d_{t}, e_{t}\right)}{\phi R}=\beta \frac{\mathbb{E}_{t}\left(u^{\prime}\left\{c_{F B}\left[d_{F B}\left(d_{t}, e_{t}\right), e_{t+1}\right], e_{t+1}\right\} e_{t+1}\right)}{u^{\prime}\left[c_{F B}\left(d_{t}, e_{t}\right)\right]\left(1-s_{t}^{*} \phi\right)},
$$

for all states $\left(d_{t}, e_{t}\right)$ satisfying (ii). Using the above equation and (26), we can solve for $s_{t}^{*}=s^{*}\left(d_{t}, e_{t}\right)$ and the solution turns out to be (28). Because $s_{t}^{*}$ is chosen to satisfy (30), (23) and (24) are obviously satisfied at the first-best allocation. Finally, using (27), (25) can be rewritten as

$$
\left[1+s^{*}\left(d_{t}, e_{t}\right)\right] u^{\prime}\left[c_{F B}\left(d_{t}, e_{t}\right)\right]=\beta R \mathbb{E}_{t}\left(u^{\prime}\left\{c_{F B}\left[d_{F B}\left(d_{t}, e_{t}\right), e_{t+1}\right]\right\}\right)+\lambda_{m}\left[d_{t}, e_{t} ; s^{*}\left(d_{t}, e_{t}\right)\right]
$$

which is exactly (22) under $s_{t}=s^{*}\left(d_{t}, e_{t}\right)$. Therefore, all the first-order conditions (22)-(24) are satisfied under $s^{*}\left(d_{t}, e_{t}\right)$. This $s^{*}$ is completely determined by the current state of the economy and hence is time-consistent.

The proposition confirms that, as in the case of the three-period model, the optimal subsidy $s^{*}\left(d_{t}, e_{t}\right)$ can achieve the first-best allocation. The mechanism behind the result is the same as that in the three-period model. The government can fully control the asset price to avoid fire sales by choosing $s_{t}$. 


\subsection{The size and frequency of bailouts}

\subsubsection{Calibration}

The parameters are mainly taken from Bianchi and Mendoza (2012). For the household's preference, $u\left(c_{t}\right)=c_{t}^{1-\sigma} /(1-\sigma)$, with $\sigma=2.0$. The discount factor $\beta$ is set to 0.96 , calibrating the model to the annual frequency. The ceiling on the household borrowing per collateral asset $\phi$ is set at 0.36 . We assume that the total factor productivity in Bianchi and Mendoza (2012) can be translated into the stochastic process of the dividend $e_{t}$ in our model. The stochastic process of the total factor productivity in Bianchi and Mendoza (2012) follows a log-normal $\operatorname{AR}(1)$ process. We thus employ the same stochastic process for $e_{t}$ as theirs: $\log \left(e_{t+1}\right)=\rho \log \left(e_{t}\right)+\eta_{t+1}$, where $\eta_{t} \sim N\left(0, \sigma_{\varepsilon}\right)$ for all $t$. Here $\rho$ and $\sigma_{\varepsilon}$ are set to 0.53 and 0.014 , respectively. To ensure stationary $d_{F B}\left(d_{t}, e_{t}\right)$, we assume that households face a small risk premium on their foreign debt. ${ }^{13}$ Specifically, we replace the budget constraint (20) with a slightly different form:

$$
c_{t}+d_{t}+p_{t} \theta_{t+1}=\theta_{t} e_{t}+\left(1+s_{t}\right) \frac{d_{t+1}}{R_{t+1}}-S_{t}+p_{t} \bar{\theta}
$$

where $R_{t+1}=R+\psi\left[\exp \left(d_{t+1}\right)-1\right], R=1.028$ and $\psi=0.01 .{ }^{14}$

To confirm that parameters are reasonably calibrated, we simulate the laissez-faire economy with the occasionally binding collateral constraint. We interpret GDP in our model as $e_{t} \bar{\theta}$. In the simulation, the mean of the debt-to-GDP ratio is 33.5 percent. This ratio is in close proximity to the calibration target in Benigno et al. (2013), who calibrate their model to the Mexican economy based on the updated dataset of Lane and Milesi-Ferretti (2007). We also compute the probability of binding collateral constraints in the laissez-faire economy as a proxy of the crisis probability. The probability is 6.57 percent, which is broadly in line with the literature. ${ }^{15}$

\footnotetext{
${ }^{13}$ See Schmitt-Grohé and Uribe (2003).

${ }^{14}$ In the appendix, which is available upon request, we show that Proposition 3 can be extended to the case with a risk premium on foreign debt.

${ }^{15}$ For reasonable values of the crisis probability, Benigno et al. (2013) target the crisis probability at 8 percent per year. In the empirical studies, Basel Committee on Banking Supervision (2010) reports two empirical crisis probabilities for 11 advanced economies over 1985-2009, based on the datasets of Reinhart and Rogoff (2008) and Laeven and Valencia (2008). The estimated crisis probabilities are 5.2 percent in Reinhart and Rogoff (2008) and 4.1 percent in Laeven and Valencia (2008).
} 


\subsubsection{Simulation results}

Table 1 compares the moments generated by the model without intervention (i.e., the laissezfaire economy) with those generated under the optimal subsidy. Overall, the optimal subsidy on debt takes extremely large values, meaning that massive bailouts are required to restore the first-best allocation. On average, $s_{t}^{*}$ is 67.0 percent. To finance this subsidy, the government needs to impose a large lump-sum tax equivalent to as much as 31.6 percent of annual household income $(e \bar{\theta})$. Figure 1 plots the simulated path of the optimal subsidy over 300 periods. The figure indicates that the government activates bailouts very frequently. In the figure, $s_{t}^{*}$ takes a value of zero only in period 13 . This means that, over 300 periods, bailouts are activated 299 times.

The reason for the massive and frequent bailouts is straightforward. Expectations of bailouts strongly incentivize households to hold a large amount of debt. As long as the debt in the first-best allocation is sufficiently large compared to that in the laissez-faire economy, the collateral constraint is likely to bind. Whenever the collateral constraint binds, the government bails out households by encouraging new borrowing that is used to repay the large amount of existing debt. Given their expectations that they will be bailed out, it is optimal for households to roll over the large amount of new borrowing. This new borrowing substantially increases the probability that the collateral constraint will continue to bind in the next period. As a result, the government almost always needs to bail out households.

We argue that there is a gap between theory and data. For comparison, we take an empirical estimate reported by Frydl (1999). Based on Frydl (1999), an empirically realistic size of a bailout would amount to somewhere between 1 to 3 percent of GDP for a single year in the aftermath of a crisis. ${ }^{16}$ Comparisons of the sizes of intervention between the model and the practice suggest that the optimal subsidy would be difficult to implement, perhaps because of political conflicts which are not taken into account in our model.

\footnotetext{
${ }^{16} \mathrm{Frydl}$ (1999) discusses two empirical works estimating (i) fiscal costs (resolution cost) and (ii) the length of financial crises as his baseline estimates (Caprio and Klingebiel, 1996 and Lindgren, Garcia, and Saal, 1996). In the two empirical papers, the average fiscal costs are 13.6 percent of GDP in the former and 7.2 percent in the latter, whereas the average duration of crises is 4.5 years and 6.2 years, respectively. We compute the average fiscal cost for a single year by dividing average total fiscal costs by the average length of financial crises, suggesting that the average fiscal cost for a single year ranges from $1.16(7.2 / 6.2)$ to 3.02 $(13.6 / 4.5)$ percent of GDP.
} 


\subsubsection{Sensitivity of simulation results}

Although unrealistically large and frequent bailouts seem difficult to implement, the size and frequency depend on parameters in the model. Therefore, one could argue that it is possible to attain a realistic size and frequency of bailouts by changing parameters in the model. To consider this argument, this subsection discusses whether the difficulty of the optimal subsidy is robust to changes in the model parameters.

Proposition 3 suggests that $s_{t}^{*}$ can take lower values under looser collateral constraint (i.e., a larger $\phi$ ). Under a larger $\phi$, the government may activate bailouts less often, because the collateral constraint is less likely to bind. Hence, in the economy with a large $\phi$, the optimal subsidy can be practically feasible. In Figure 2, we plot the optimal subsidy in the economy with $\phi=0.60$. With this parameterization, the maximum value of $s_{t}^{*}$ over 300 periods is 2.90 percent and the size of policy intervention measured by the lump-sum tax relative to GDP is 1.71 percent. On the frequency, the incidence of the policy activation is two out of 300 periods. Thus, bailouts appear to be easier to implement in an economy with $\phi=0.60$. However, the model fails to explain crisis probabilities under the laissezfaire economy: in our simulations, the probability of binding collateral constraints in the laissez-faire economy is only 0.25 percent, much lower than that reported in the previous studies. Therefore, it is sensible to conclude that, although an "optimal bailout" may be implementable in an economy resilient to negative shocks, it would not be feasible in most economies that are fragile to shocks.

The optimal subsidy $s_{t}^{*}$ can be also affected by the risk-premium parameter $\psi$. In our benchmark simulation, $\psi$ is set to a somewhat large value of 0.01 . In the literature on the small open economy real business cycle model, this parameter is usually set to a very small number to calibrate the model without the collateral constraint to match the volatility of the debt-to-GDP ratio. For example, Schmitt-Grohé and Uribe (2003) set this parameter to 0.0007. We could have used their parameterization, but the level of the debt in this case is much higher than what we obtained in the benchmark simulation. Because (28) indicates that a larger amount of foreign debt increases the size and frequency of bailouts, this low $\psi$ makes the optimal subsidy more unrealistic. 


\section{Concluding remarks}

This paper analyzed the roles of bailouts in managing financial crises. Using the simple framework employed by Jeanne and Korinek (2010), we showed that the timing assumption of the collateral constraint has a non-negligible impact on the debate regarding macro prudential policies and bailouts. If we employ Jeanne and Korinek's (2010) original functional form of the collateral constraint, the policy that subsidizes debt during crises does not increase the welfare, and thus this bailout fails to outperform the prudential capital controls. If households can collateralize their assets that they purchase at the same time as their borrowing, the same policy can improve the welfare much more than the prudential capital controls. Our analytical results in the deterministic three-period model can be extended into a more general stochastic infinite-horizon framework. Using the extended model, we examined the practical feasibility of the optimal subsidy on debt. In terms of the practical feasibility, however, the optimal subsidy would be massive in size and require very frequent activation. We conclude that, while an "optimal bailout" is theoretically feasible, in practice it would be difficult to implement.

We presented our results in the simplified models to obtain the results analytically. As in the seminal works by Jeanne and Korinek (2010) and Bianchi (2011), we considered an endowment economy without an endogenous labor supply. To extend the analysis into a more general framework would be an important step for future research.

\section{References}

[1] Basel Committee on Banking Supervision, 2010, "An Assessment of the Long-Term Economic Impact of Stronger Capital and Liquidity Requirements," http://www.bis.org/publ/bcbs173.htm.

[2] Benigno, G., H. Chen, C. Otrok, A. Rebucci, and E. R. Young, 2012a, "Capital Controls or Exchange Rate Policy? A Pecuniary Externality Perspective," Federal Reserve Bank of St. Louis Working Paper No. 2012-025A.

[3] Benigno, G., H. Chen, C. Otrok, A. Rebucci, and E. R. Young, 2012b, "Optimal Policy for Macro-Financial Stability," Federal Reserve Bank of St. Louis Working Paper No. 2012-041. 
[4] Benigno, G., H. Chen, C. Otrok, A. Rebucci, and E. R. Young, 2013, "Financial Crises and Macro-Prudential Policies," Journal of International Economics, 89 (2), pp. 453470.

[5] Bianchi, J., 2011, "Overborrowing and Systemic Externalities in the Business Cycle," American Economic Review, 101 (7), pp. 3400-3426.

[6] Bianchi, J., 2013, "Efficient Bailouts?" unpublished manuscript.

[7] Bianchi, J., and E. G. Mendoza, 2012, "Overborrowing, Financial Crises, and 'Macroprudential' Policy," unpublished manuscript.

[8] Bianchi, J. and E. G. Mendoza, 2013, "Optimal Time-consistent Macroprudential Policy," NBER working paper No. 19704.

[9] Caprio, G., and D. Klingebiel, 1996, "Bank Insolvencies: Cross-Country Experience," Policy Research Working Paper No. 1620, World Bank.

[10] Dávilla, E., 2011, "Dissecting Fire Sales Externalities," unpublished manuscript.

[11] Farhi, E. and I. Werning, 2012, "Dealing with Trilemma: Optimal Capital Controls with Fixed Exchange Rates," NBER working paper No. 18199.

[12] Farhi, E. and I. Werning, 2013, "A Theory of Macroprudential Policies in the Presence of Nominal Rigidities," unpublished manuscript.

[13] Frydl, E. J., 1999, "The Length and Cost of Banking Crises," IMF Working Paper, $\mathrm{WP} / 99 / 30$.

[14] Green, E. J., 2010, "Bailouts," Economic Quarterly, 96 (1), pp. 1-32.

[15] Jeanne, O., and A. Korinek, 2010, "Excessive Volatility in Capital Flows: A Pigouvian Taxation Approach," American Economic Review, 100 (2), pp. 403-407.

[16] Jeanne, O., and A. Korinek, 2011, "Managing Credit Booms and Busts: A Pigouvian Taxation Approach," unpublished manuscript.

[17] Jeanne, O., and A. Korinek, 2012, "Macroprudential Regulation versus Mopping Up after the Crash," unpublished manuscript. 
[18] Kehoe, T. J., and D. Levine, 1993, "Debt-Constrained Asset Markets," Review of Economic Studies, 60 (4), pp. 865-888.

[19] Kiyotaki N. and J. Moore, 1997, "Credit Cycles," Journal of Political Economy, 105 (2), pp. 211-248.

[20] Korinek, A., 2011, "The New Economics of Prudential Capital Controls: A Research Agenda," IMF Economic Review, 59 (3), pp. 523-561.

[21] Korinek A. and A. Simsek, 2013, "Liquidity trap and Excessive Leverage," unpublished manuscript.

[22] Laeven, L., and F. Valencia, 2008, "Systemic Banking Crises: A New Database," IMF Working Paper No. WP/08/224.

[23] Lane, P. R., and G. M. Milesi-Ferretti, 2007, "The External Wealth of Nations Mark II: Revised and Extended Estimates of Foreign Assets and Liabilities, 1970-2004," Journal of International Economics, 73 (2), pp. 223-250.

[24] Lindgren, C. J., G. G. Garcia, and M. I. Saal, 1996, Bank Soundness and Macroeconomic Policy, International Monetary Fund.

[25] Reinhart, C., and K. Rogoff, 2008, "Banking Crises: An Equal Opportunity Menace," NBER Working Paper No. 14587.

[26] Schmitt-Grohé, S., and M. Uribe, 2003, "Closing Small Open Economy Models," Journal of International Economics, 61 (1), pp. 163-185.

[27] Schmitt-Grohé, S. and M. Uribe, 2012, "Prudential Policy for Peggers," NBER working paper No. 18031.

[28] Schmitt-Grohé, S. and M. Uribe, 2013, "Downward Nominal Wage Rigidity, Currency Pegs, and Involuntary Unemployment," unpublished manuscript. 
Table 1: Average and standard deviations of the variables

\begin{tabular}{ccc}
\hline \hline & Laissez-faire economy & Bailouts \\
\hline Debt & 0.335 & 0.471 \\
& $(0.016)$ & $(0.045)$ \\
Asset price & 0.962 & 1.273 \\
& $(0.018)$ & $(0.121)$ \\
Consumption & 0.990 & 0.985 \\
& $(0.015)$ & $(0.009)$ \\
\hline Subsidy (percent) & - & 67.0 \\
Fiscal cost (percentage of GDP) & - & $(22.4)$ \\
& & 31.6 \\
\hline \hline
\end{tabular}

Note: The numbers in each entry report the average and the standard deviations of the debt position, asset price, and consumption in the laissez-faire economy and the economy with bailouts. The numbers without parentheses refer to the average of variables, and the numbers in parentheses below the average are the standard deviations of the corresponding variables. These moments are from the numerically approximated ergodic distributions with 1,000 periods and 1,000 simulations. The second column also reports the average and standard deviation of the optimal subsidy and the fiscal cost of bailouts measured by the lump-sum tax relative to the GDP. 
Figure 1: Simulated path of $s_{t}^{*}$ : Benchmark calibration

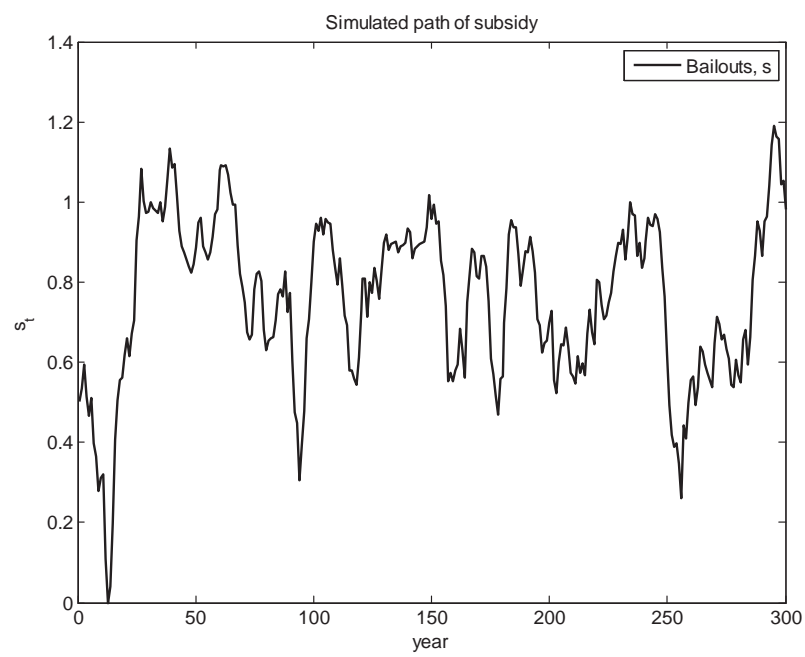

Figure 2: Simulated path of $s_{t}^{*}$ : Economy with $\phi=0.60$

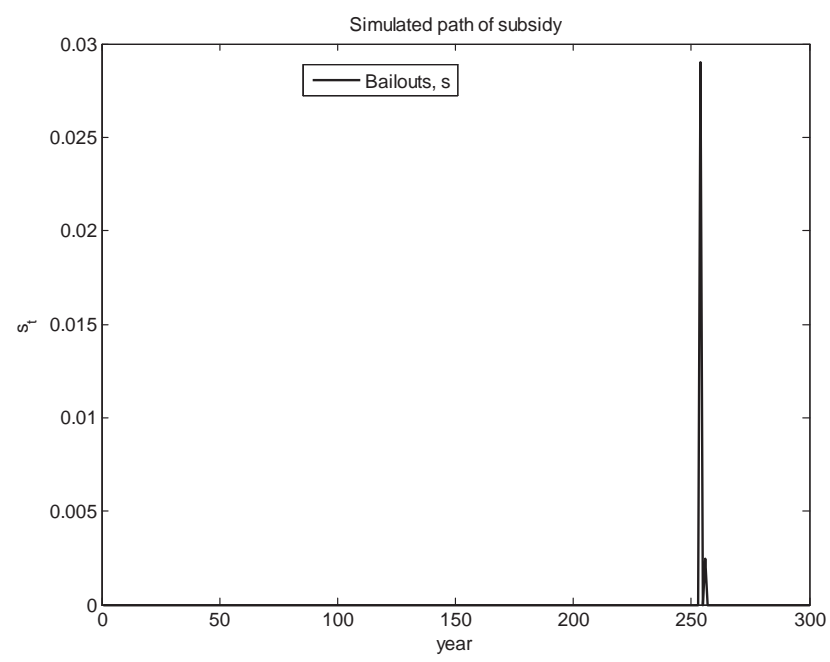

